\title{
Severe accidental hypothermia: a brief review of the literature
}

\author{
Les Gordon, FRCA
}

\section{Les Gordon is a consultant anaesthetist with University Hospitals of Morecambe Bay, and team doctor with the Langdale Ambleside Mountain Rescue Team.}

\section{Essential learning points}

- Severe accidental hypothermia is a core temperature $<28^{\circ} \mathrm{C}$

- It is a reversible cause of cardiac arrest because it is treatable in appropriate patients if the clinician recognises the features and knows what to do

- Refractory arrhythmias and cardiac arrest are the biggest problems in the early stages of resuscitation

- Management involves advanced techniques and will require an admission to intensive care

- With correct patient selection and management, the prognosis is excellent

\section{INTRODUCTION}

Hypothermia is defined as a core body temperature below $35^{\circ} \mathrm{C}$. (I) The term 'accidental' is used to differentiate unintentional hypothermia from the deliberate hypothermia that is used in medical practice. Hypothermia can be classified clinically as primary (accidental) caused by exposure to a cold environment, or secondary due to a variety of medical conditions such as spinal cord injury, pancreatitis, myxoedema and sepsis.

Severe accidental hypothermia is a core temperature $<28^{\circ} \mathrm{C}$ and is an uncommon occurrence. Nevertheless, it is important to be aware of the special requirements of these patients, particularly if accompanied by cardiac arrest. Patients with severe accidental hypothermia may appear to be dead, yet have the potential for full recovery with appropriate management. This has given rise to the guiding principle that 'no one is dead until warm and dead. (I) A prolonged period of cardiopulmonary resuscitation (CPR) may be required, yet patients have survived even after 6.5 hours of CPR.(2) Passive methods of rewarming are ineffective in these cases. Invasive methods are the mainstay of treatment, but may only be available at specialist centres. Following resuscitation, the patient is likely to need a prolonged period in intensive care and rehabilitation. In many cases, the prognosis can be excellent if appropriate measures are taken promptly. This article will review the current published best practice for these cases. It can be read in conjunction with the case report published in this issue in which local staff successfully managed a case a few years ago. (See pages 184 to 186)

\begin{abstract}
A BRIEF HISTORY
The effects of exposure to extreme cold or wet have been recognised for thousands of years. The signs were well described by one of Napoleon's surgeons in his journal written during the retreat from Moscow, and deaths from cold used to be collected in official statistics in the USA and the UK. Hypothermia as an entity could not be diagnosed until it became possible to measure body temperature in the late 19th century. ${ }^{33}$ However, it was not until the 1960s, when a report described 23 incidents which produced 25 deaths, that it became clear that exposure to a more temperate climate can also lead to hypothermia particularly if other factors are present such as wetting, wind and exhaustion. ${ }^{(4,5)}$ This is not surprising. The ambient temperature in the UK is usually significantly below body temperature, even on a summer's day. Therefore, a person who is not participating in physical activity will tend to cool down to the environmental temperature unless well insulated. Although hypothermia is seen as an outdoor hazard, it has been reported in an unconscious patient rescued from an air-conditioned building. ${ }^{(6)}$
\end{abstract}

\section{CATEGORIES OF HYPOTHERMIA}

Accidental hypothermia can be categorised by speed of onset and severity.

\section{Speed of onset ${ }^{(2)}$}

\section{Grade of hypothermia by speed of onset}

- Acute hypothermia (also called immersion hypothermia) is caused by sudden exposure to overwhelming cold such as immersion in cold water or entrapment in an avalanche. The body cools rapidly before energy reserves are exhausted. There has been no time for a cold diuresis (see below).

- Sub-acute hypothermia (exhaustion hypothermia) occurs over several hours. It is caused by exposure to moderately cold environments, particularly in the presence of wet and/or wind, in combination with a lack of food and physical exhaustion. Unlike in acute hypothermia, glucose stores are depleted so that heat can no longer be generated by shivering.

- Chronic hypothermia occurs in conditions of mild cold and comes on over a period of days or weeks. It is mainly seen in the elderly. 


\section{Severity}

This is graded according to core body temperature. ${ }^{(1.8)}$

\section{Severity of hypothermia by core body temperature}

- Mild $\left(35-32^{\circ} \mathrm{C}\right)$

- Moderate $\left(32-28^{\circ} \mathrm{C}\right)$

- Severe $\left(<28^{\circ} \mathrm{C}\right)$

- A fourth category of profound is sometimes used to denote a temperature of $20^{\circ} \mathrm{C}$

A practical way for on-site staging of hypothermia is that of the International Commission for Mountain Emergency Medicine (ICAR-MEDCOM) that relates the clinical signs to body temperature (see box). This is particularly useful as it is unlikely that it will be possible to measure core temperature in the field. The patient's temperature range can be estimated from the clinical features. ${ }^{(9)}$ Currently, $13.7^{\circ} \mathrm{C}$ is the lowest recorded body temperature due to accidental hypothermia from which an adult has survived and made a complete recovery. ${ }^{(10)}$ The lowest temperature for infant survival is $14.8^{\circ} \mathrm{C}$, (11) and $14.2^{\circ} \mathrm{C}$ for a child. ${ }^{(12)}$

\section{ICAR-MEDCOM on-site staging of hypothermia}

- Stage I-Clearly conscious and shivering $\left(35-32^{\circ} \mathrm{C}\right)$

- Stage II - Impaired consciousness without shivering $\left(32-28^{\circ} \mathrm{C}\right)$

- Stage III - Unconscious $\left(28-24^{\circ} \mathrm{C}\right)$

- Stage IV - Apparent death $\left(24-13.7^{\circ} \mathrm{C}\right)$

- Stage $V$ - Death due to irreversible hypothermia $\left(<13.7^{\circ} \mathrm{C}\right)$

\section{PHYSIOLOGICAL EFFECTS OF HYPOTHERMIA ${ }^{(7,8,13,14)}$}

Thermogenesis by shivering can increase heat production by 2-5 times. Peak shivering occurs at a body temperature of $35^{\circ} \mathrm{C}$. This gradually decreases as the temperature falls but when it actually stops varies in different reports..$^{(14)}$ This may reflect body energy supplies, as shivering cannot continue when glycogen stores are depleted, which usually occurs when the body temperature is in the low 30s.

\section{CARDIAC EFFECTS OF SEVERE ACCIDENTAL HYPOTHERMIA}

\section{Cardiovascular system}

The initial response to cold is vasoconstriction, which causes blood to be shunted from the periphery to the core. This protective effect is prevented by ethanol. Vasoconstriction fails when the temperature is $<24^{\circ} \mathrm{C}$ and heat loss increases further. There is an initial tachycardia in response to the physical stress and the increased cardiac output required for shivering. This response fails with progressive hypothermia so that at $25^{\circ} \mathrm{C}$, the cardiac index is $45 \%$ normal.
The greatest problem in the management of severe hypothermia is the effect on cardiac conduction. ${ }^{(15)}$ At temperatures $<32^{\circ} \mathrm{C}$, the most characteristic ECG abnormality is the J (Osborn) Wave at the end of the QRS complex (see figure). The heart rate gradually slows, reaching about $50 \%$ of the normal resting rate at $28^{\circ} \mathrm{C}$. This is caused by decreased spontaneous depolarisation of pacemaker cells, so it is therefore resistant to atropine. At lower temperatures, the bradycardia increases, reaching about ten beats per minute at $20^{\circ} \mathrm{C}$. (14) There is a high likelihood of sudden asystole when the temperature is $\angle 24^{\circ} \mathrm{C}$. ${ }^{(14,15)}$ Atrial fibrillation is common, but usually converts back to sinus rhythm spontaneously whethe heart is rewarmed. A cardiac output may still be

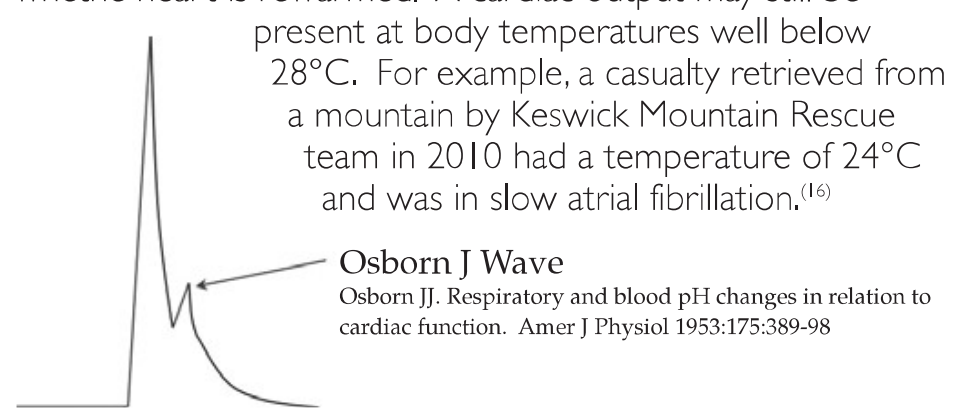

Below $32^{\circ} \mathrm{C}$, all types of arrhythmias may be seen. Conduction delay through the AV node leads to any degree of atrioventricular block. ST elevation or depression and T-wave inversion may also occur, indicating increasing myocardial acidosis and ischaemia. The duration of QRS complexes increases. QT prolongation occurs, ${ }^{(15)}$ and can persist for days after rewarming. ${ }^{(14)}$

Ventricular fibrillation (VF) is increasingly likely to occur spontaneously as the temperature falls below about $29^{\circ} \mathrm{C} .{ }^{(13)}$ Severe hypothermia decreases the myocardial fibrillatory threshold so that VF may be triggered just by seemingly innocuous stimuli such as moving the casualty, ${ }^{(17)}$ or some invasive procedures, eg insertion of a central venous catheter. Patients in ICAR-MEDCOM Stage II or worse should be kept lying horizontal as raising the legs can cause an influx of cold blood from the peripheries into the core and this can be enough to lower the cardiac temperature sufficiently to trigger $V F_{1}^{(I)}$

\section{Should hypothermic patients be intubated?}

It has been suggested that VF can be precipitated by tracheal intubation. However, reports from three large series of patients suggests that this risk may have been overstated and is in fact related to a failure to preoxygenate the patient. (2) In one series, intubation was performed on 117 patients, of which 97 had a temperature of $<32^{\circ} \mathrm{C}$. All were preoxygenated and no arrhythmias occurred. ${ }^{(18)}$ The relative safety of intubation in the presence of adequate oxygenation is illustrated by a study on anaesthetised dogs. ${ }^{(19)}$ The animals were intubated and extubated every two degrees starting at $27^{\circ} \mathrm{C}$. There was only one episode of VF during 42 intubations performed at temperatures $<28^{\circ} \mathrm{C}$, whereas there were eight separate episodes of spontaneous VF unrelated to intubation in five dogs.

\section{Treating arrhythmias}

All arrhythmias are extremely resistant to defibrillation and all current drugs. Once VF has occurred, a review of case reports suggests that successful defibrillation is sometimes possible in patients with temperatures at or below $30^{\circ} \mathrm{C}$. (20,21) If it occurs, 
refractory VF usually continues until the heart rewarms to $28-30^{\circ} \mathrm{C}$. Many case reports illustrate the ineffectiveness of traditional methods for treating VF in severely hypothermic patients. In one such case, there were 13 attempts at defibrillation, five doses of adrenaline, two doses of atropine, and two doses of amiodarone administered in the first hour. ${ }^{(22)}$ All were unsuccessful.

Resuscitation Council guidelines state that defibrillation can be attempted if an ECG monitor indicates an appropriate arrhythmia, but if VFNT persists after three shocks, further defibrillation should not be attempted until the core temperature is above $30^{\circ} \mathrm{C}$. (1) Adrenaline, amiodarone and atropine should be withheld until the patient has been rewarmed to $30^{\circ} \mathrm{C}$. Once this temperature has been reached, the drug administration intervals should be doubled in comparison with normothermia because drug metabolism is slower, leading to potentially toxic levels if repeated doses are given. (I)

In an animal model, subjects with a temperature as low as $30^{\circ} \mathrm{C}$ exhibited a better response to defibrillation than normothermic animals. ${ }^{(23.24)}$ However, this picture is not seen in clinical situations. This may be because in addition to species differences, study animals are usually anaesthetised beforehand and this may affect outcome. In addition, the duration of hypothermia in these experiments is considerably less than that seen in the clinical setting.

Normothermic patients who have suffered a cardiac arrest are at increased risk for re-fibrillation. ${ }^{(25,26)}$ The situation is the same in hypothermia, particularly whilst the cardiac temperature (rather than the body temperature) is below about $30^{\circ} \mathrm{C}$ for the reasons described above.

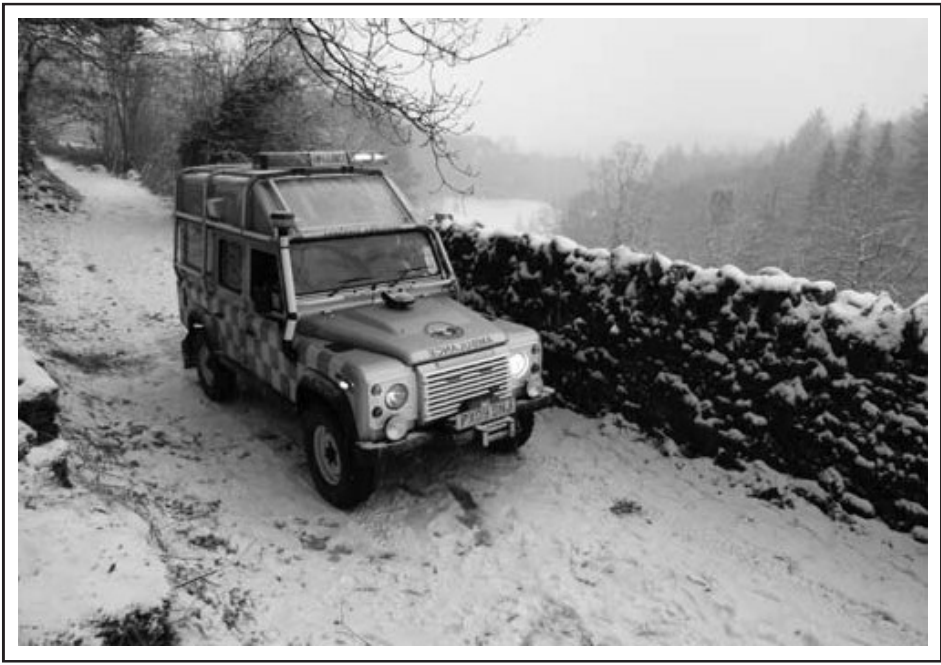

\section{Central nervous system}

In mild hypothermia, patients are often lethargic or confused and may exhibit altered states of judgement. The phenomenon of 'paradoxical undressing', sometimes seen on the mountains, is when the sufferer removes their warm clothing even though they are literally freezing to death. This is believed to be due to fatiguing of peripheral vasoconstriction so that the peripheries become flooded with warmer blood from the core. ${ }^{(27)}$ Reflexes become increasingly sluggish as body temperature falls and become absent as the temperature falls below about $28^{\circ} \mathrm{C}$. The pupils become dilated and unreactive to light at this temperature. ${ }^{(14)}$ The EEG becomes flat below about $20^{\circ} \mathrm{C}$. Cerebrovascular autoregulation remains intact until the temperature drops below $25^{\circ} \mathrm{C}$. (8,14) Below $35^{\circ} \mathrm{C}$ there is a decrease in cerebral metabolism by $6-10 \%$ per $1{ }^{\circ} \mathrm{C}$ fall in core temperature. ${ }^{(1.8)}$ This decrease in cerebral oxygen requirements protects the brain against ischaemic damage after cardiac arrest. At a body temperature of $20^{\circ} \mathrm{C}$, the ischaemic tolerance of the brain is increased tenfold compared to normothermic conditions. ${ }^{(28)}$

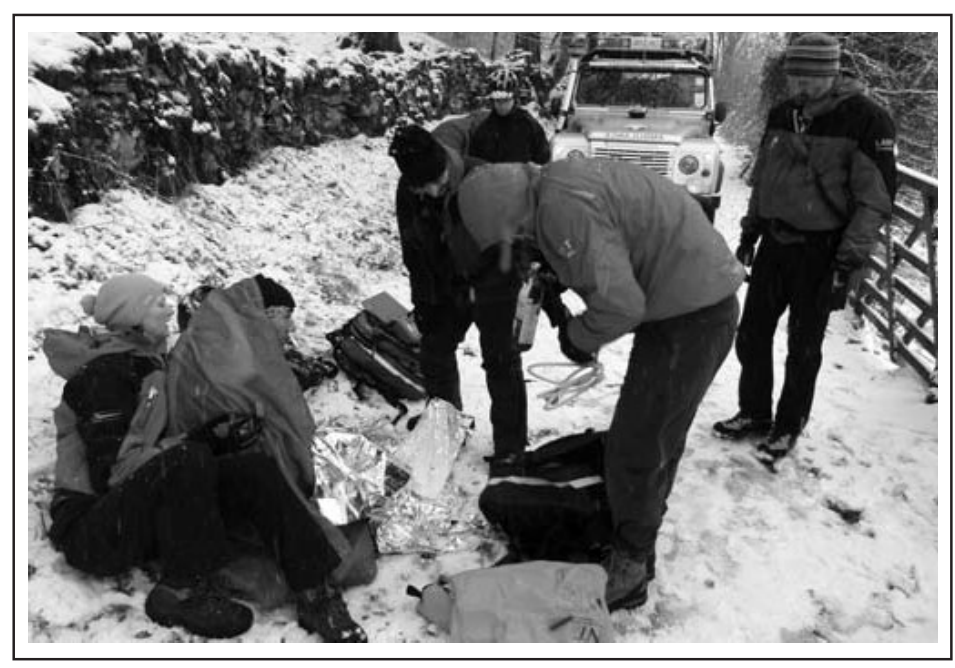

\section{Respiratory system}

As the body temperature falls, the tidal volume, respiratory rate, pulmonary compliance and thoracic elasticity decrease. The respiratory rate may only be five breaths per minute when the body temperature is below $30^{\circ} \mathrm{C}$. The cough reflex is obtunded and there is an increase in the volume and viscosity of secretions. This can lead to atelectasis. Hypoxaemia is therefore likely to be present. It should be remembered when ventilating these patients that $\mathrm{CO}_{2}$ production falls by $50 \%$ for each $8^{\circ} \mathrm{C}$ fall in temperature, ie it is about $50 \%$ of normal at $30^{\circ} \mathrm{C}$. Nevertheless, there can be a respiratory acidosis due to centrally mediated respiratory depression. The oxygen-haemoglobin dissociation curve shifts to the left leading to decreased oxygen release from haemoglobin into the tissues at low partial pressures of oxygen. Body oxygen consumption falls by approximately $6 \%$ per $1{ }^{\circ} \mathrm{C}$ fall in core temperature and reaches $50 \%$ at $28^{\circ} \mathrm{C}$, $75 \%$ at $22^{\circ} \mathrm{C}$ and $92 \%$ at $10^{\circ} \mathrm{C}$.

\section{Renal, fluid balance, acid-base and electrolytes}

There is an initial cold-induced diuresis. This is partly due to the relative central hypervolaemia resulting from peripheral vasoconstriction, but also from a reduction in antidiuretic hormone release and an absence of thirst. The presence of ethanol will double the diuresis. Acute renal failure is seen in almost half of the patients admitted to an intensive care unit (ICU). ${ }^{(14)}$ Changes in vascular permeability lead to a loss of plasma into the extravascular space, which exacerbates the hypovolaemia caused by the diuresis. ${ }^{(14)}$ This causes haemoconcentration, with an increase in haematocrit of about $2 \%$ for every $1{ }^{\circ} \mathrm{C}$ fall in temperature. Renal blood flow and glomerular filtration rate fall to $50 \%$ at $27^{\circ} \mathrm{C}$. Blood urea and creatinine levels rise reflecting dehydration. Hyperglycaemia is common and is due to catecholamine-induced glycogenolysis, decreased insulin release and inhibition of insulin transport. This exacerbates the hypovolaemia by causing an osmotic diuresis. 
Hypothermia can cause a mixed acidosis. In addition to a respiratory acidosis (mentioned above), there is a metabolic component due to lactate from shivering and poor tissue perfusion. Hepatic function is also depressed so lactate is not metabolised. Blood gases are difficult to interpret in hypothermic patients. The solubility of $\mathrm{CO}_{2}$ and $\mathrm{O}_{2}$ in plasma increases, and $\mathrm{CO}_{2}$ production falls. Blood gas samples are analysed at $37^{\circ} \mathrm{C}$. When evaluating and acting on the blood gas results, it is important to know whether they are corrected or not. If the arterial $\mathrm{PaCO}_{2}$ and $\mathrm{pH}$ are reported at the patient's temperature, the $\mathrm{pH}$ will be higher and the $\mathrm{PaCO}_{2}$ lower than in normothermia, but there is little data on what the normal should be in hypothermia. It is therefore easier to appreciate acid-base disturbance if the results are uncorrected. $\mathrm{O}_{2}$ is different because the left shift of the oxygen-haemoglobin dissociation curve means that for any given oxygen content, the $\mathrm{PaO}_{2}$ will be lower than in normothermia. When the blood sample is rewarmed to $37^{\circ} \mathrm{C}$, the dissociation curve shifts back, but since the oxygen content has not changed, the $\mathrm{PaO}_{2}$ will rise and appear artificially high. Therefore, to maintain true $\mathrm{PaO}_{2}$ in the normal range, the measured $\mathrm{PaO}_{2}$ should be corrected for current body temperature. ${ }^{(29,30)}$

Serum electrolytes fluctuate with temperature, duration of exposure, and the rewarming technique selected. Both membrane permeability and sodium-potassium pump efficiency change with temperature. Plasma electrolyte levels are also affected by ongoing fluid shifts, the state of hydration prior to cooling, rehydration, and endocrine or gastrointestinal dysfunction. Hyperkalaemia has a particular significance as a prognostic indicator (see below).

\section{Blood}

There are a number of reports of disseminated intravascular coagulopathy with no obvious cause other than the hypothermia. ${ }^{(14)}$ The action of clotting factors is impaired at low temperature. For example, the activated partial thromboplastin time is increased by $50 \%$ at $29^{\circ} \mathrm{C}$. This may be missed in the laboratory as the blood is warmed to $37^{\circ} \mathrm{C}$ before testing. Importantly, the reversible clotting defect created by hypothermia cannot be corrected by transfusion, as the infused clotting factors will cool down to body temperature and fail to function. Rewarming will reactivate the clotting mechanism. Platelet dysfunction occurs, and thrombocytopaenia develops possibly due to sequestration of platelets in the spleen.

\section{Other effects}

Rhabdomyolysis has been described as a complication following severe hypothermia and appears to be related to immobility, (7) The extremities are vulnerable to frostbite due to the peripheral vasoconstriction, hypoperfusion, and haemoconcentration leading to 'sludging' of red blood cells in the small blood vessels. ${ }^{(7)}$

\section{INWHICH PATIENTS SHOULD RESUSCITATION BE ATTEMPTED?}

In spite of the guiding principle that 'no one is dead until they are warm and dead', in view of the costs, time and effort involved, there is a responsibility to ensure that, where possible, attempts are only made to resuscitate patients who stand a chance of being resuscitated. It is actually fair to say that sometimes 'people are dead when they're cold and dead'.(31)
A patient who is severely hypothermic often appears dead with a very slow, small volume, irregular pulse and unrecordable blood pressure. Nevertheless, although extremely low, the cardiac output but may be just sufficient to meet minimal metabolic demands. Triage criteria can be used to help differentiate those who appear dead from those who really are dead. Four factors should be considered as contraindications to resuscitation when assessing nonperfusing, severely hypothermic victims.

\begin{tabular}{l} 
Reasons not to start resuscitation \\
- Presence of asphyxia, eg avalanche victims, \\
- ${ }^{(32)}$ drowning ${ }^{(38)}$ \\
- Presence of injuries incompatible with life \\
chest CPR \\
- Probable core temperature below $10-12^{\circ} \mathrm{C}$ \\
\hline
\end{tabular}

The presence of extreme hyperkalaemia is generally believed to reflect a period of asphyxia prior to the onset of hypothermia. ${ }^{(32)} \mathrm{A}$ level of $>10 \mathrm{mmol} / \mathrm{L}$ has been seen as an indicator of non-survival in an animal model, ${ }^{(33)}$ and human case reviews. ${ }^{(34,35)}$ However, a child with a potassium of $11.8 \mathrm{mmol} / \mathrm{L}$ was resuscitated from a temperature of $14.2^{\circ} \mathrm{C}$, ${ }^{(12)}$ so the upper limit may be different in children. The current recommendation for avalanche victims is a cut-off of $12 \mathrm{mmol} / \mathrm{L}^{(1,9,33)}$ Relevant factors that can raise plasma potassium and potentially lead to an error in triage are suxamethonium, ${ }^{(36)}$ and compression injury.

Victims of submersion may develop hypothermia. If this occurs in icy water $\left(<5^{\circ} \mathrm{C}\right)$, hypothermia may develop sufficiently quickly to provide some neurological protection against hypoxia, ${ }^{(1)}$ particularly in children. ${ }^{(37)}$ If the water temperature is $>6^{\circ} \mathrm{C}$, survival is unlikely if submersion is $>30$ minutes. By contrast, if the water temperature is $6^{\circ} \mathrm{C}$ or below, the survival time is extended to 90 minutes, beyond which survival is extremely unlikely. ${ }^{(38)}$

\section{PREHOSPITAL MANAGEMENTT(1,8)}

The rescuer can expect that casualties with ICAR-MEDCOM Stage II or worse will have an irritable myocardium, hypovolaemia and a large temperature gradient between the periphery and the core. Any injuries should be stabilised, and the casualty should be immobilised and handled carefully. Oxygen should be administered, as requirements will increase as the body rewarms, particularly if shivering occurs. The body should be dried and insulated. Wet clothes should be cut off to prevent excessive movement of the casualty that can occur during undressing.

Conscious patients who are mildly hypothermic should be given hot sweet drinks to help with rewarming and provide a substrate to allow shivering to occur. They can be allowed to mobilise as movement increases heat production and is more effective at rewarming than shivering. By contrast, movement can be risky in more severely hypothermic casualties because muscle activity will pump cold blood from the peripheries back to the core. The airway must be patent, and protected if necessary with intubation. This will also ensure good oxygenation. It is important to remember that the pressure in 


\title{
Case report and commentary
}

\author{
Andrzej Szymczakowski, MD; Paul Grout, FCEM; Commentary by Lucy Belson, RGN
}

A middle-aged woman was rescued from a river on a freezing night. At the scene, her Glasgow Coma Score (GCS) was 6/15 $(2,2,2)$, with a blood pressure of $130 / 90 \mathrm{mmHg}$, a heart rate $56 / \mathrm{min}$, a respiratory rate of 12 breaths $/ \mathrm{min}$ and an $\mathrm{SpO}_{2}$ of $99 \%$ on $101 /$ min of oxygen via facemask. The transport to hospital took approximately 40 minutes. In the ambulance, she suffered an asystolic cardiac arrest. CPR was commenced, her trachea was intubated and $1 \mathrm{mg}$ of iv adrenaline was administered.

Staff in hospital deployed a mechanical cardiac compression device (Auto-Pulse ${ }^{\ominus}$, Zoll) because it was assumed that she would need a prolonged period of cardiorespiratory support because of her hypothermia $\left(20.7^{\circ} \mathrm{C}\right.$ on admission). This provided sufficient cardiac output to produce a palpable radial pulse. Core warming was commenced by use of an intravenous infusion of $0.9 \%$ saline through a fluid warmer, gastric/bladder lavages and external warming with the use of a warming blanket. Intermittent positive pressure ventilation with humidified oxygen was started approximately 40 minutes post-admission and radial artery and internal jugular vein cannulation was performed. After insertion of the arterial catheter, the direct arterial pressure remained at $60 / 20 \mathrm{mmHg}$ so it was decided to repeat the dose of $1 \mathrm{mg}$ adrenaline, which resulted in increase of arterial pressure to $110 / 40 \mathrm{mmHg}$. After two hours of continuous bladder/gastric lavage and mechanical ventilation with $100 \%$ humidified oxygen, the core temperature increased from $21^{\circ} \mathrm{C}$ to $25^{\circ} \mathrm{C}$.

We interrupted chest compression only for essential measures such as central vein cannulation, chest $\mathrm{X}$-ray and battery changes for the Auto-Pulse machine. Initial arterial gases showed a lactic acidosis, good oxygen exchange, normocapnia and a significant hypokaleamia. In the initial two hours, $4 \mathrm{mg}$ of adrenaline was given in $1 \mathrm{mg}$ increments (achieving pressures of $100 / 40 \mathrm{mmHg}$ ). Following this period, we transferred to the intensive care unit (ICU). We placed a haemofiltration line in the right femoral vein for access for veno-veno haemofiltration (CVVH) as a further means of core warming.

We used a continuous infusion of adrenaline $(0.44 \mathrm{mg} / \mathrm{kg} / \mathrm{min})$, potassium $(50 \mathrm{mmol} / 3 \mathrm{~h})$, magnesium $(16 \mathrm{mmol} / 2 \mathrm{~h})$ and insulin $(6-10 \mathrm{u} / \mathrm{h})$ during this initial period after admission to ICU. Haemofiltration was started with an exchange rate of $5,000 \mathrm{ml} /$ hour and with fluid removal of $100 \mathrm{ml} / \mathrm{h}$. The filter temperature (the temperature of substitution fluid) was set at the maximum setting of $38.5^{\circ} \mathrm{C}$ and an infusion of normal saline, through a fluid warmer, at a rate of $100 \mathrm{ml} / \mathrm{h}$, maintained a neutral fluid balance: 5,000 units of heparin were added to the priming fluid and further doses were to be guided by activated clotting time measurement, after a low dose heparin infusion $(4 \mathrm{u} / \mathrm{kg} / \mathrm{h})$ had begun. The core temperature had risen to $28^{\circ} \mathrm{C}$ within two hours, but the patient remained in asystole and unresponsive to several attempts of external cardiac pacing.

Four and a half hours after resuscitation had been commenced, all available batteries for the Auto-Pulse and physical strength of the available staff to substitute for battery power had been exhausted. Failure seemed imminent. At this point, it was felt that there was little to be lost by deviating from standard protocols and we used a single 200J biphasic DC shock in asystole. To our surprise and relief, spontaneous sinus rhythm returned for a few minutes but then changed to ventricular fibrillation (VF). A second defibrillation was unsuccessful so it was necessary to continue with chest compressions and use amiodarone, again a desperate measure outwith the normal recommendations. A third DC defibrillation resulted in a sinus bradycardia and restoration of sustained cardiac output output. A significant amount of adrenaline $(3.26 \mathrm{mg} / \mathrm{kg} / \mathrm{min})$ and noradrenaline was needed together with $3 \mathrm{mg}$ of atropine to maintain satisfactory blood pressure during the first ten to 15 minutes of spontaneous circulation. The broad ECG complexes initially observed on the monitor narrowed over the first 30 minutes of spontaneous circulation. When cardiac output had improved, we sedated the patient: $100 \mathrm{mls}$ of blood-stained urine was noted in the urinary bag, triggering a decision to give $125 \mathrm{mls}$ of $20 \%$ mannitol, which effectively provoked a diuretic response. CVVH, fluid infusion and notropes were continued.

Haemofiltration was discontinued after eight hours. At this stage, it was possible to reduce inotropic support. We introduced forced alkaline diuresis with normal saline $(100 \mathrm{ml} / \mathrm{hr})$ and $1.26 \%$ sodium bicarbonate $(100 \mathrm{ml} / \mathrm{hr})$ infusions and four incremental doses of $20 \mathrm{mg}$ frusemide to prevent the renal complications of rhabdomyolysis. We are pleased to report that the patient was fit to be discharged from hospital a few days later.

\section{DISCUSSION}

Rarely do NHS staff get exposed to such cases. In this case, the late-night presentation presented logistical difficulties as there were few staff available for the sustained physical effort of cardiopulmonary resuscitation.

The use of a mechanical compression liberates the limited number of night staff from performing prolonged and physically exhausting chest compressions, and generated a better cardiac output, confirmed on invasive arterial monitoring, than staff were able to achieve performing manual external cardiac massage.

To our knowledge, simultaneous use of a mechanical compression device and CVVH has not been described in the literature before. Neither the Resuscitation Council (UK) ${ }^{(1)}$ nor the American Heart Association ${ }^{(2)}$ in recommending the use of extracorporeal blood warming with partial bypass in hypothermic cardiac arrest, mention CVVH. We are aware of only two cases reporting successful resuscitation from hypothermic cardiac arrest with the use of CVVH ${ }^{(3,4)}$ This seems to suggest CVVH is either not considered as a tool in this setting or its efficacy is not adequate. Indeed, assuming a theoretical speed of rewarming of $2-3^{\circ} \mathrm{C} / \mathrm{h},^{(1)}$ the time to achieve a temperature at which re-occurrence of spontaneous circulation (ROSC) can take place or death can be confirmed could be estimated as longer then six hours in our patient. It should be mentioned that the $2-3^{\circ} \mathrm{C} / \mathrm{h}$ gradient comes from patients who maintained their own circulation. Our case, as well as the one presented by Alfonzo ${ }^{(3)}$ revealed a slower than described rewarming gradient $\left(1^{\circ} \mathrm{C} / \mathrm{h}\right)$, which in both cases resulted in delivery of electric shocks in asystole. In our case, continuation of chest compressions became impossible, because of exhaustion of the team. ROSC occurred earlier in the case presented by Hughes ${ }^{(4)}-$ at a temperature of $23^{\circ} \mathrm{C}$ with $2^{\circ} \mathrm{C} / \mathrm{h}$ rewarming gradient - when an additional heat 
source was used on the return line of the CVVH machine. Faster warming of the heart with a delay in distribution of heat within the central compartment could be a possible explanation, but without direct measurements this is pure assumption. In both cases, circulation re-occurred after defibrillation in non-shockable rhythms.

Treatment modalities varied in each case. Hughes used transfusion of blood products to treat anaemia and clotting abnormalities. We used infusions of inotropes, insulin, potassium and magnesium. Exchanging volumes differed we used a so-called 'septic cycle', with up to $60 \mathrm{ml} / \mathrm{kg} /$ hour of fluid exchange, whereas Alfonzo's case reports flow of up to $200 \mathrm{ml} / \mathrm{min}$. In both cases, haemofiltration was discontinued following ROSC; however, we made the decision to continue with haemofiltration for several hours using high-flow fluid exchange. There is some data suggesting that use of highflow haemofiltration can contribute to prevention of acute renal failure caused by myoglobin.(5,6) Our patient did not require either renal replacement therapy or intermittent positive airway pressure ventilation after extubation.

Guidelines are useful for medical practice but the authors accept that occasionally a clinical situation occurs in which guidelines can be ignored. This is particularly important where it is felt that there is nothing to be lost by deviation. In this case, we deviated from the guidelines in five respects:

- we used adrenaline as we felt fit and ignored advice about its lack of efficacy in hypothermia

- we used DC defibrillation in asystole

- we used $100 \%$ oxygen only until we established an arterial line, thereafter we were guided by laboratory measurements of arterial $\mathrm{PaO}_{2}$

- we used amiodarone in hypothermia

- we used insulin and other infusions - potassium, magnesium

Use of warmed and humidified oxygen/inspiratory gas mixture is a basic and effective method of warming a hypothermic patient, but to our knowledge neither ambulances nor emergency departments in the UK are equipped with such devices. Our patient received oxygen, via a facemask, from a bottled supply, prior to arrival in the emergency department. Oxygen administered in this way is dry and cold and could have contributed to the cooling of the patient. Need for gas warmers and humidifiers mandates early transfer to an intensive care area.

The use of vasopressors and amiodarone in patients with hypothermic cardiac arrest is not standard practice according to the Resuscitation Council (UK) or the American Heart Association ${ }^{(1,2)}$ A recently published literature review, however, suggests re-evaluation of these guidelines in cases of ventricular fibrillation. (7) In our case, the use of adrenaline, initially in increments followed by continuous infusion guided by values of invasive blood pressure, provided physiologically normal mean arterial pressures (MAP) Considering coronary perfusion pressures from experimental data, and its obvious dependency on MAP, the use of adrenaline in hypothermic cardiac arrest may be beneficial. Most probably, this is one of those rare cases (if not the only one in the literature) in which direct arterial pressures were measured during resuscitation and the use of catecholamines guided by its measurement.

Glycaemic control during prolonged resuscitation seems to be an underestimated measure in the presence of other serious life-threatening disturbances. Hyperglycaemia in patients undergoing on-pump coronary artery by-pass graft is associated with increased risk of neurocognitive dysfunction. ${ }^{(8)}$ After admission to the ICU, an insulin infusion was commenced and the highest glucose level was $24.8 \mathrm{mmol} / 1$ just after spontaneous circulation was restored. This dropped to $15 \mathrm{mmol} / \mathrm{l}$ over the next two hours. Including the resuscitation and rewarming time and recognising the inotropic role of insulin, ${ }^{(9,10)}$ in our opinion, insulin should be used to stabilise glycaemia in similar cases, even before spontaneous circulation is restored.

\section{CONCLUSIONS}

The use of a mechanical cardiac compression device is effective in maintaining cardiac output for a prolonged period in cardiac arrest in severely hypothermic patients.

CVVH is a potentially useful means of extracorporeal core rewarming and can be used in conjunction with a mechanical cardiac compression device.

Further studies on the use of vasopressors and insulin in hypothermia and hypothermic cardiac arrest are needed to define their definitive role in hypothermia.

Use of defibrillation in apparent asystole in hypothermic cardiac arrest with a core temperature below $30^{\circ} \mathrm{C}$ requires further experimental evaluation.

\section{REFERENCES}

1. Resuscitation Council (UK). Advanced Life Support. 5th Ed. Revised June 2008. Chapter 13. Pp123-4

2. 2005 American Heart Association Guidelines for Cardiopulmonary Resuscitation and Emergency Cardiovascular Care. Circulation 2005;112(Suppl 1); IV136-8

3. Alfonzo A, Lomas A, Drummond I, McGugan E. Survival after 5-h resuscitation attempt for hypothermic cardiac arrest using CVVH for extracorporeal rewarming. Nephrol Dial Transplant 2009;24:1054-6

4. Hughes A, Riou P, Day C. Full neurological recovery from profound $\left(18^{\circ} \mathrm{C}\right)$ acute accidental hypothermia: successful resuscitation using active invasive rewarming techniques. Emerg Med J 2007;24:511-12

5. Naka T, Jones D, Baldwin I, et al. Myoglobin clearance by super high-flux hemofiltration in a case of severe rhabdomyolysis: a case report. Crit Care 2005;9(2):R90-5

6. Ronco C. Extracorporeal therapies in acute rhabdomyolysis and myoglobin clearance. Crit Care 2005;9:141-2

7. Wira C, Becker J, Martin G, Donnino M. Anti-arrhythmic and vasopressor medications for the treatment of ventricular fibrillation in severe hypothermia: a systematic review of literature. Resuscitation 2008;78(1):21-9

8. Puskas F, Grocot HP, White WD, Mathew JP, Newman MF, Bar-Yosef S. Intraoperative hypeglycemia and cognitive decline after CABG. Ann Thorac Surg 2007;84(5):1467-73

9. Farah AE, Alousi AA. Minireview: the actions of insulin on cardiac contractility. Life Sci 1981;29:975-1000

10. Tune JD, Mallet RT, Downey HF. Insulin improves cardiac contractile function and oxygen utilization efficiency during moderate ischemia without compromising myocardial energetics. J Mol Cell Cardiol 1998;30:2025-35 


\section{Commentary ...}

Lucy Belson is the senior resuscitation officer responsible for training staff across all the hospital sites.

This is a challenging case involving prolonged chest compressions for a hypothermic patient. The use the mechanical chest compression (MCC) device (AutoPulse ${ }^{\oplus}$ Zoll), along with other interventions, played a key role in this patient's survival from a four and half hour cardiac arrest.

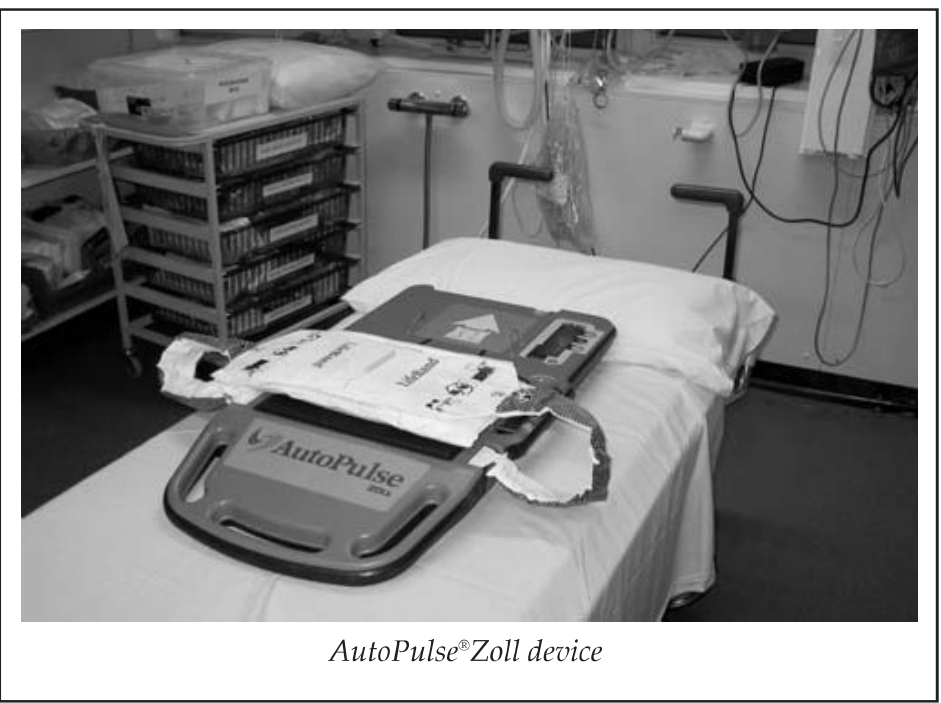

The evidence that manual chest compressions are poor already exists. ${ }^{(1)}$ Kern suggests that only $30-40 \%$ of normal blood flow to the brain is achieved through manual chest compressions, whereas mechanical chest compressions give improved haemodynamics including coronary perfusion. ${ }^{(2,3)}$

I certainly hope that this case stimulates further discussion. For example, should MCC be considered an essential piece of equipment in all Emergency Departments (EDs)? I strongly support this, and it is the case that MCC is currently used in a number of London hospitals. Two minutes of manual chest compressions is physically tiring; EDs are usually extremely busy and can at times be short staffed; there is evidence to show that manual chest compressions are not very effective it's a strong case. We could go further and ask if all emergency ambulances should have an MCC device. There are obvious drawbacks to performing chest compression in the back of a moving ambulance: it's a danger to the paramedics and is unlikely to be sufficiently effective.

The resuscitation department has previously run the 'Zoll CPR Challenge'. This is when staff are asked to perform two minutes of chest compressions on a manikin which is connected up to a laptop and defibrillator. This then gives frighteningly accurate feedback on the quality of chest compressions, including both rate and depth. It is often a humbling experience: the machine does not recognise the status or experience of the participant. In 2008 a porter from Westmorland General Hospital was watching the challenge being performed in the main entrance. Towards the end of the day he came over and said he'd give it a go as no-one else was around. He was outstanding and scored more than any other participant (and, by the way, he was 68 years old at the time).

Clinical staff must keep their basic life support skills up to date on an annual basis and the resuscitation department has a number of sessions available. To book onto our courses please go to the KELD pages of the trust intranet and click on resuscitation, where there are details on how to book a session.

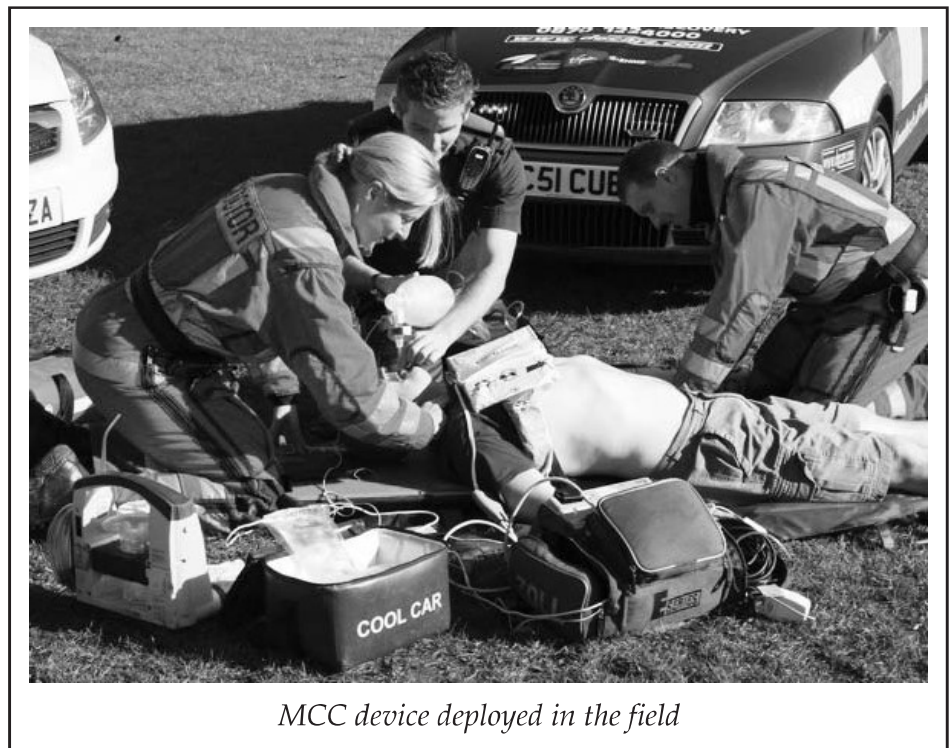

Although this has been a rare event, shouldn't we prepare ourselves for it becoming much more common? Countries such as Canada, Switzerland and the Scandinavian countries deal with this on a regular basis and it would be interesting to explore this further - particularly if our very cold British winters continue!

Ms Lucy Belson Senior Resuscitation Officer University Hospitals of Morecambe Bay NHS Foundation Trust

\section{REFERENCES}

1. Kern KB. CPR challenges: perfusion. Ballieres Clin Anaesthesiol 2000:14 (3):591-609

2. Ornato JP, Peberdy MA, Edwards DP, Dhindsa H, Overton JL. Improvement in field return of spontaneous circulation using circumferential chest compression cardiopulmonary resuscitation. Prehosp Emerg Care 2003;9:1

3. Timerman S, Cardoso FL, Ramires JAF, Halperin $\mathrm{H}$. Improved hemodynamic performance with a novel chest compression device during treatment of in-hospital cardiac arrest. Resuscitation 2004; 61:273-80

\section{Clinical staff must keep their basic life support skills up to date on an annual basis and the resuscitation department has a number of sessions available. To book onto our courses please go to the KELD pages of the trust intranet and click on resuscitation, where there are details on how to book a session.}




\section{Continued from page 183}

the tracheal tube cuff will rise substantially as the patient is rewarmed. A common error in intubated patients is overenthusiastic ventilation. Hypocapnia can induce ventricular irritability. ${ }^{(8)}$

Palpation of pulses is extremely difficult in vasoconstricted patients with a bradycardia and hypotension. The rescuer should auscultate and palpate for at least one minute to find pulses. An ECG monitor can be useful. Importantly, iatrogenic VF can easily occur if chest compressions are used when not indicated. The management of cardiac arrest has been outlined above.

\section{PRACTICALITIES OF MEASURING CORE TEMPERATURE}

The ideal is to measure oesophageal temperature, as this not only gives the core but most importantly, the cardiac temperature. The probe tip must be behind the heart so as not to give a falsely high reading from warmed tracheal air. In prehospital areas, an oral device is available that measures down to $26^{\circ} \mathrm{C}$. Some rescue teams use thermometers that were designed for non-clinical purposes, with a long-reach probe which is inserted into the oesophagus. Rectal temperature can be misleading. It can read falsely low if the legs are frozen or during rewarming if the probe tip is inserted into a mass of cold faeces when it will lag well behind oesophageal temperature, ${ }^{(8,10)}$ or falsely high if peritoneal lavage is used for rewarming.

\section{INITIAL MANAGEMENT IN HOSPITAL ${ }^{(7,8)}$}

Casualties who are brought directly to the Emergency Department should be managed along similar lines to those described above. However, there are many more options in hospital. Invasive monitoring can be used, though it is wise to avoid placing catheters in the heart as these can precipitate an arrhythmia. Traditional monitoring is usually unhelpful, eg pulse oximetry, non-invasive blood pressure. Doppler ultrasonography can be used to search for evidence of cardiac activity. A full general blood screen should be done bearing in mind the caveats outlined above about interpreting the blood results of hypothermic patients when the assays are run at normal body temperature. In addition, it is appropriate to check for specific items, eg thyroid function, cortisol, toxicology, etc in cases of secondary hypothermia.

Fluid resuscitation will be required for the reasons outlined above. Most patients will be significantly dehydrated. Fluid shifts within the body will reverse during rewarming. However additional crystalloid will be required for the fluid lost by diuresis. Lactate solutions such as Hartmann's solution should not be used initially as the cold liver cannot metabolise the lactate. ${ }^{(8)}$ Intravenous fluid replacement should be continued throughout the rewarming phase as the peripheral circulation opens up.

\section{STRATEGIES FOR REWARMING ${ }^{(1,7)}$}

It must be remembered that cardiovascular stability will only be achieved by stopping the fall in core temperature and establishing rewarming. There are three different principles for rewarming: passive external, active external and active internal.

Indications for active rewarming
- - Moderdiovascular instability
- Inadequate rate of rewarming or failure to rewarm
- Endocrine insufficiency causing decreased heat
- Production (thyroid, adrenal, pituitary, etc)
- Pbligatory vasodilation caused by drugs or poisons
cord injury, multiple sclerosis, etc

\section{Passive rewarming}

Passive rewarming means that the patient raises their own body temperature, and intervention is limited to applying full body insulation and a warm environment. It is only appropriate in conscious patients who have mild hypothermia but are still able to shiver or move around to generate heat. In addition, the patient should be given hot sweet drinks to provide an energy substrate to allow shivering to continue.

\section{Active rewarming}

Active rewarming is the direct application of exogenous heat to the patient. The indications are: ${ }^{(8)}$

\section{Active external rewarming}

This delivers heat directly to the skin. Examples include forced-air blanket such as the Bair Hugger ${ }^{\circledR}$, immersion, plumbed garments such as the Artic Sun ${ }^{\circledR},{ }^{(39)}$ hot water bottles, heating pads and radiant heat sources. Whole body immersion in hot water should not be done, but immersing the extremities in hot water at $42^{\circ}$ or $45^{\circ} \mathrm{C}$ can give rewarming rates between $6.1^{\circ}$ and $9.9^{\circ} \mathrm{C}$ per hour in mild hypothermia by opening cutaneous arteriovenous anastomoses. ${ }^{(7,8)}$ Radiant heat and heating pads are also helpful. Active external warming with blankets has been shown to increase temperatures by $1-2^{\circ} \mathrm{C} /$ hour. ${ }^{(23)}$ Forced air rewarming is very effective in severe hypothermia without cardiac arrest, rewarming at about $1.7^{\circ} \mathrm{C} /$ hour..$^{(7,40)}$ Focussing the rewarming around the torso produces a fast core rewarming rate. ${ }^{(41)}$

\section{Active internal (core) rewarming}

Many options are available for active internal warming, Examples are:

- Warmed humidified air raises core temperature by $1-1.5^{\circ} \mathrm{C} /$ hour. ${ }^{(23)}$ Breathing accounts for about $21 \%$ of total heat loss, ${ }^{(42)}$ so airway rewarming minimises respiratory heat loss if the temperature and moisture content is high enough. Passive heat-moisture exchangers are less effective than active devices. ${ }^{(8,43)}$

- Heated intravenous infusions. ${ }^{(8)}$

- Lavage of a body cavity or large organ with warmed fluid peritoneal, gastric, colonic, bladder, mediastinal, and pleural (thoracic) ${ }^{(44,45)}$ - have all been described. ${ }^{(8)}$ These will raise the core temperature by about $1-2.5^{\circ} \mathrm{C} /$ hour. ${ }^{(18,23)}$ 


\section{Extracorporeal rewarming}

Three routinely available methods have been used for rewarming the blood outside the body:

- Continuous venovenous haemofiltration, which can raise the core temperature by about $1-3^{\circ} \mathrm{C} /$ hour. , $^{(7,46,4,47,48,49)}$

- Haemodialysis, which can raise the core temperature by about $2-3^{\circ} \mathrm{C} /$ hour..$^{(8,47,50.51)}$

- Rewarming via a multi lumen femoral vein catheter that is usually used to produce hypothermia in patients with cardiac arrest. Warm water at $37.5^{\circ} \mathrm{C}$ can be circulated through the balloons that run along the catheter. However, it only rewarms at about $0.75^{\circ} \mathrm{C}$ per hour..$^{(52.53)}$

The drawback with these techniques is that they do not support the circulation. If they are to be used in a patient without a perfusing rhythm, then arrangements must be made to continue CPR, perhaps for many hours, until the heart has rewarmed sufficiently to be able to achieve and sustain a circulation. In the presence of severe hypothermia with cardiorespiratory arrest, the priority is to restore a perfusing rhythm as quickly as possible by rewarming rapidly - well in excess of $2^{\circ} \mathrm{C}$ per hour - in order to minimise the length of time necessary for CPR. This can only be achieved using cardiopulmonary bypass (CPB) or extracorporeal membrane oxygenation (ECMO). These methods produce the most rapid rewarming $\left(8-12^{\circ} \mathrm{C} / \text { hour }\right)^{(1)}$ - whilst obviating the need for continuing CPR during the rewarming period. Rewarming speeds greater than $10-12^{\circ} \mathrm{C}$ are technically possible, but evidence suggests that this can be dangerous because the temperature gradient between the circulating blood and the cold tissue is too great. ${ }^{(8)}$

The medical literature contains many case reports and retrospective reviews dating back to the 1980s that confirm the effectiveness of CPB and ECMO for rewarming casualties with severe hypothermia who have had a cardiac arrest, and this is the method recommended in the latest Resuscitation Council guidelines. (I) CPB is generally done via the femoral vessels in this situation, and is extremely effective. ${ }^{(5,54,5,5,5,5,5,58)}$ A portable CPB device that is normally employed in the management of cardiogenic shock has been used successfully to rewarm hypothermic patients. It has the advantages over traditional CPB of low cost, is less invasive, and has a short setup time. ${ }^{(59)}$ ECMO also works extremely well, though it is less generally available in the UK. It has a number of potential advantages over CPB including less systemic heparinisation, it can be used for prolonged respiratory support, and it may cause less of an inflammatory response than CPB. Survival rates may be higher with ECMO. ${ }^{(7,60)}$

A recent comprehensive review has provided a practical approach to the prehospital management of severe accidental hypothermia and recommends transfer of appropriate cases directly to a facility able to deliver CPB or ECMO. (7) If a severely hypothermic patient with cardiac arrest has initially been brought to a hospital without a cardiac unit, then there will obviously be a practical problem with transferring them to another facility for rewarming. If transfer is possible, eg by helicopter, then it should be considered. Chest compressions will have to be maintained using a mechanical device such as the Zoll AutoPulse or the Physio-Control LUCAS ${ }^{\mathrm{T}}$. The Zoll device has received a certificate of airworthiness and has been used during flight by a number of Air Ambulances in the UK. ${ }^{(61)}$
Core temperature afterdrop

Afterdrop is a further fall in temperature that occurs after removal from the cold. The main mechanism appears to be as equilibration occurs between the periphery and the core, cold blood moves from the limbs and causes a fall in core temperature. The incidence and magnitude vary widely. It is more likely to occur when a large temperature gradient exists between the periphery and the core, ie in dehydrated, chronically cold patients. It can also occur if core rewarming is too rapid leaving the peripheries still very cold. For these reasons, it is unwise to try to stimulate the peripheral circulation or raise the legs in severely hypothermic individuals. In cold-water immersion, post-rescue collapse may also result from abrupt hypotension after loss of the hydrostatic squeezing effect of the water. ${ }^{(7.8)}$

\section{THE POST-WARMING PHASE FOR VICTIMS OF SEVERE HYPOTHERMIA}

Survivors of the initial phase face several problems. These are related to the hypothermia and the rewarming technique. Examples are cardiac dysfunction, acute renal failure, ARDS, or similar. Some have even needed ECMO for 3-4 days because of oxygenation problems. Neurological problems are common but usually resolve in time. Although some patients recover within days, most have needed a protracted period (weeks) in intensive care. However, once they have got as far as ICU, the longterm prognosis is generally very good. Examples of the problems that can occur are:

- A skier became partially trapped under ice over a stream and was clinically dead when pulled out. At the scene, basic CPR was carried out and was continued in a helicopter for 90 minutes until arrival at hospital. Femoral access CPB was established 130 minutes after arrest. During rewarming, VF started which spontaneously converted to a perfusing rhythm at an oesophageal temperature $31.5^{\circ} \mathrm{C}$ (pharyngeal temperature $25^{\circ} \mathrm{C}$, rectal temperature $14.2^{\circ} \mathrm{C}$ ). The patient subsequently required ECMO for 5 days, was in ICU for 28 days, and had a postillness polyneuropathy. On day 60 she was moved to a rehabilitation unit and returned to work after five months. ${ }^{(10)}$

- A 26-year-old man was found in a forest 15 hours after a suicide attempt. His core temperature was $19^{\circ} \mathrm{C}$ (oesophageal) with circulatory arrest (VF). Defibrillation failed and he was transferred to hospital whilst receiving continuous CPR. Femoral access CPB was instituted. Rewarming took 158 minutes and he was weaned from CPB without inotropes. He spent eight days on the general ICU. The only complication was rhabdomyolysis. The patient was discharged from hospital four weeks after the event. ${ }^{(62)}$

\section{CONCLUSION}

The outcome can be extremely good, particularly in young people, with survival rates reaching $60-70 \%{ }^{(10,57,63,64,65)}$ If hypothermia is associated with trauma and acidosis (the 'Lethal Triad'), the mortality rate is very high. ${ }^{(66)}$ Severe accidental hypothermia is a challenging clinical problem, yet many patients can be saved by awareness of the issues 
involved. Given the complexity and rarity of the condition, all hospitals with A\&E departments should have clear guidelines for managing these patients effectively. The development of such guidelines should involve the relevant emergency services

Finally, an International Registry has been set up to collect information on patients with severe accidental hypothermia (see http://www.hypothermia-registry.org). The aim is to increase knowledge about the subject, and enable comparison of rewarming techniques and outcomes. Any doctor can add patients to the database and extract information.

\section{Photographs courtesy of Nick Owen (LAMRT)}

\section{REFERENCES}

I. Soar J, Perkins GD, Abbas G, et al. European Resuscitation Council Guidelines for 2010. Section 8: Cardiac arrest in special circumstances. Resuscitation 2010;81:1400-33

2. Lloyd E. Accidental Hypothermia. Resuscitation 1996;32: | | |-24

3. Guly $H$. History of accidental hypothermia. Resuscitation 2011;82:122-5

4. Pugh LGCE. Accidental hypothermia in walkers, climbers and campers: a report to the Medical Commission on Accident Prevention. Br Med J 1966;1:123-9

5. Coleman E, Doddakula K, Meeke R, et al. An atypical case of successful resuscitation of an accidental profound hypothermia patient, occurring in a temperate climate. Perfusion 2010;25(2): 103-6

6. Udy AA, Ziegenfuss MD, Fraser JF. Deep accidental hypothermia during the Queensland summer. Crit Care Resusc 2007;9:341-3

7. Peek GJ, Davis PR, Ellerton JA. Management of Severe Accidental Hypothermia. Yearbook Int Care Emerg Med (2008). Springer. Pp 147-59

8. Accidental Hypothermia. In:Wilderness Medicine. Auerbach P. (Ed.). Elsevier. 2012

9. Durrer B, Brugger H, Syme D. The medical on-site treatment of hypothermia: ICAR-MEDCOM Recommendation. High Alt Med Biol 2003;4:99-103

10. Gilbert M, Busund R, Skagseth A, Nilsen PÅ, Solbø JP, Resuscitation from accidental hypothermia of $13.7^{\circ} \mathrm{C}$ with circulatory arrest. Lancet 2000;355:375-6

I I. Sargant N, Sen ES, Marden B. Too cold for comfort: a neonate with severe hypothermia. Emerg Med J doi: | 0.1 | 36/emermed-20| |-200479

12. Dobson J, Burgess J]. Resuscitation from severe hypothermia by extracorporeal rewarming in a child. J Trauma 1996;40(3):483-5

13. Zimmerman JL. Hypothermia, hyperthermia and rhabdomyolysis. ACCP Crit Care Med Board Rev. 20th Ed 2009;20:32 I-32; doi: | 0.1378/ccmbr.20th.32 I

14. Mallet ML. Pathophysiology of accidental hypothermia. Q J Med 202;95:775-85

15. Matu A, Brady WJ, Perron AD. Electrocardiographic manifestations of hypothermia. Amer J Emerg Med 2002;20(4):314-26
16. Keswick Mountain Rescue Team Annual Report. 2010 (http://www.keswickmrt.org.uk/)

17. Lee CH, van Gelder C, Burns K, et al. Advanced cardiac life support and defibrillation in severe hypothermic cardiac arrest. Prehospital Emergency Care 2009; I 3:85-9

18. Danzl DF, Pozos RF. Multicenter hypothermia survey, Annals Emerg Med 1987; | 6(9): 1042-55

19. Gillen JP,Vogel MFX, Holterman RK, et al. Ventricular fibrillation during orotracheal intubation of hypothermic dogs. Ann Emerg Med 1982; I5(4):412-6

20. Clift J, Munro-Davies L. Is defibrillation effective in accidental severe hypothermia in adults? Emerg Med J 2007;24:50-

21. Thomas R, Cahill C). Successful defibrillation in profound hypothermia (core body temperature $25.6^{\circ} \mathrm{C}$ ). Resuscitation 2000:47:317-20

22. Smith T, Berk AS, Upadhyay $H$. Severe hypothermia in a patient with spinal cord injury without radiological abnormality. J Emerg Trauma Shock 20 I 1;4(3):42 I-4

23. Rhee B], Zhang Y, Boddicker KA, et al. Effect of hypothermia on transthoracic defibrillation in a swine model. Resuscitation 2005;(65):79-85

24. Boddicker AK, Zhang Yi, Zimmerman MB, et al. Hypothermia improves defibrillation success and resuscitation outcomes from VF. Circulation 2005; | | 1:3195-3201

25. White RD, Russell JK. Refibrillation, resuscitation and survival in out-of-hospital sudden cardiac arrest victims treated with biphasic automated external defibrillators. Resuscitation 2002;55: 17-23

26. Van Alem AP, Post J, Koster RW. VF recurrence: characteristics and patient outcome in out-of-hospital cardiac arrest. Resuscitation 2003;59:181-8

27. Wedin B,Vanggaard L, Hirvonen J. 'Paradoxical undressing' in fatal hypothermia. J Forensic Sci 1979;24(3):543-53 http://www.ncbi.nlm.nih.gov/pubmed/54l 627 (accessed $27 / 1 / 12)$

28. Althaus U, Aeberhard P, Schüpbach P, et al. Management of profound accidental hypothermia with cardiorespiratory arrest. Annals Surg 1982; 195(4):492-5

29. Bacher A. Effects of body temperature on blood gases Int Care Med 2005;3 I ( I):24-7

30. Polderman $\mathrm{KH}$, Ingeborg $H$. Therapeutic hypothermia and controlled normothermia in the intensive care unit: Practical considerations, side effects, and cooling methods. Crit Care Med 2009;37(3): I 10 I-20

31. Auerbach P. Some people are dead when they're cold and dead (Editorial). JAMA 1990;264(|4): | 856-7

32. Boyd J, Brugger $H$, Shuster M. Prognostic factors in avalanche resuscitation: a systematic review. Resuscitation 2010;81:645-52

33. Kjægaard B, Jakobsen LK, Nielson C, et al. Low plasma potassium in deep hypothermic cardiac arrest indicates that cardiac arrest is secondary to hypothermia: a porcine study. Eur J Emerg Med 2010; 17(3): | 31-5

34. Schaller M-D, Fischer AP, Perret CH. Hyperkalaemia: $A$ prognostic factor during severe hypothermia. JAMA 1990;264: | 842-5 
35. Hauty MG, Esrig BC, Hill JG, et al. Prognostic factors in severe accidental hypothermia: Experience from the Mount Hood tragedy. JTrauma 1987;27:1 107-12

36. Laycock JRD, Loughman E. Suxamethonium-induced hyperkalaemia following cold injury. Anaesthesia 1986:41:739-41

37. Bolte RG, Black PG, Bowers RS, Thorne JK, Cornell HM. The use of extracorporeal rewarming in a child submerged for 66 minutes. JAMA 1988;260(3):377-9

38. Tipton MJ, Golden FSt.C. A proposed decision-making guide for the search, rescue and resuscitation of submersion (head under) victims based on expert opinion. Resuscitation 2011;82:819-24

39. Vince SC, Flint NJ, Hall AP. A novel non-invasive warming technique in severe accidental hypothermia. Resuscitation 2007;77(I): 144-5

40. Kornberger E, Schwarz B, Lindner KH, et al. Forced air surface rewarming in patients with severe accidental hypothermia. Resuscitation 1999;41: 105-I I

4I. Hultzer MV, Xiaojiang X, Marrao C, et al. Pre-hospital torso-warming modalities for severe hypothermia: a comparative study using a human model. Can J Emerg Med 2005;7(6):378-86

42. Branson RD, Chatburn RL. Humidification of inspired gases during mechanical ventilation. Resp Care 1993;38(5):46 I-8

43. Gross JL, Park GR. Humidification of inspired gases during mechanical ventilation. Minerva Anest 2012 (in press) (http://www.minervamedica.it/en/journals/minervaanestesiologica/article.php?cod=R02Y9999N00A0335 accessed 6/2/12)

44. Kjægaard B, Bach P. Warming of patients with accidental hypothermia using warm water pleural lavage. Resuscitation 2006;68:203-7

45. Plaisier BR. Thoracic lavage in accidental hypothermia with cardiac arrest - report of a case and review of the literature. Resuscitation 2005;66:99-104

46. Hughes A, Riou P, Day C. Full neurological recovery from profound (I 8 C) acute accidental hypothermia: successful resuscitation using active rewarming techniques. Emerg Med J 2007;24:51 I-12

47. Spooner K, Hassani A. Extracorporeal rewarming in a severely hypothermic patient using venovenous haemofiltration in the accident and emergency department. J Accid Emerg Med 2000; 17:422-4

48. Alfonzo A, Lomas A, Drummond l, et al. Survival after 5-h resuscitation attempt for hypothermic cardiac arrest using $\mathrm{CWVH}$ for extracorporeal rewarming. Nephrol Dial Transplant 2009;24:1054-6

49. Komatsu S, Shimomatsuya T, Kobuchi T, et al. Severe accidental hypothermia successfully treated by rewarming strategy using continuous venovenous hemodiafiltration system. J Trauma 2007;62(3):775-6

50. Sultan N, Theakston KD, Butler R, et al. Treatment of severe accidental hypothermia with intermittent hemodialysis. Can J Emerg Med 2009; I I (2): 174-7
51. Caluwe R, Shondt A. Hemodialysis as a treatment of severe accidental hypothermia. Artif Organs 2010;34(3):237-9

52. Willekes T, Naunheim R, Lasater M. A novel method of intravascular temperature modulation to treat severe hypothermia. Emerg Med J 2006;23:e56

53. Ban LH, Leone $M$, Blasco $V$, et al. A novel intravascular rewarming method to treat severe hypothermia. Eur Emerg Med 2008; $15(1): 56-8$

54. Silfvast T, Pettilä $\vee$. Outcome from severe accidental hypothermia in Southern Finland - a 10-year review. Resuscitation 2003;59:285-90

55. Ko CS, Alex J, Jeffries S, et al. Dead? Or just cold: profoundly hypothermic patient with no signs of life. Emerg Med J 2002; 19:478-9

56. Farstad M, Andersen KS, Koller M-E, et al. Rewarming from accidental hypothermia by extracorporeal circulation. A retrospective study. Eur J Cardiothor Surg 200 |;20:58-64

57. Simek M, Hajek R, BrukV, et al. Accidental deep hypothermia with cardiac arrest. Prompt complete recovery after rewarming by extracorporeal circulation. Case report. Biomed Pap Med Fac Univ Palacky 2007; I I I ( I):95-7

58. Saxena P, Shehatha J, Boyt A, et al. Role of extracorporeal circulation in the management of accidental deep hypothermia. Heart Lung Circ 2009; I 8:4 I 6-8

59. Morita S, Inokuchi S, Yamagiwa T, et al. Efficacy of portable and percutaneous cardiopulmonary bypass rewarming versus that of conventional internal rewarming for patients with accidental deep hypothermia. Crit Care Med 201 I;39(5): 1064-8

60. Ruttmann E, Weissenbacher A, Ulmer H, et al. Prolonged extracorporeal membrane oxygenation-assisted support provides improved survival in hypothermic patients with cardiocirculatory arrest. J Thor Cardiovasc Surg 2007; 134:594-600

61. Pers comm. Anne Weaver, London HEMS. Stuart Elms, Hertfordshire and Essex Air Ambulance

62. Brát R, Skorpil J, Suk M, et al. Rewarming from severe accidental hypothermia with circulatory arrest. Biomed Pap 2004; | 48:5 |-3

63. Walpoth BH,Walpoth-Aslan BN, Mattle HP, et al. Outcome of survivors of accidental deep hypothermia and circulatory arrest treated with extracorporeal blood warming. New Eng J Med 1997;337: 1500-5

64. Vassal T, Benoit-Gonin B, Carrat F, et al. Severe Accidental Hypothermia Treated in an ICU - Prognosis and outcome. Chest 200 |; 120:1998-2003

65. Walpoth BH, LocherT, Leupi F, et al. Accidental deep hypothermia with cardiopulmonary arrest: extracorporeal blood rewarming in I I patients. Eur I Cardiothor Surg 1990;4:390-3

66. Gregory J, Greiser W, Luterman A, et al. Hypothermia in trauma victims: An ominous predictor of survival. J Trauma 1987;27(9): 1019-24 